\title{
Group Work: A Way towards Enhancing Quality Learning
}

\author{
Jannatul Ferdouse ${ }^{1}$ \\ ${ }^{1}$ Department of English, Daffodil International University, Dhaka, Bangladesh \\ Correspondence: Jannatul Ferdouse, Department of English, Daffodil international University, Prince Plaza, 4/2, \\ Sobhanbag, Dhanmondi, Dhaka-1207, Bangladesh. Tel: 880-191-522-1559. E-mail: jannatfr635@gmail.com
}

Received: October 26, 2014 Accepted: December 14, 2014 Online Published: January 3, 2015

doi:10.5430/ijelt.v2n1p56 URL: http://dx.doi.org/10.5430/ijelt.v2n1p56

\begin{abstract}
Nowadays in the language teaching classrooms, the major concern of the teachers is to engage the learners in the classroom learning procedure and as a consequence, collaborative language learning is being prioritized day by day. Hence, group work is being used in the language classrooms to foster students' engagement and involvement and thus to enhance quality participation of the learners. In this respect, the purposes of this paper are to find out whether group work can help the students to actively take part in the learning process as well as to investigate whether the teacher can manage the group work successfully. Therefore, this paper aims to explore (through a case study) whether the rationales behind group work execute as true in the classroom practice.
\end{abstract}

Keywords: group work, engagement, involvement, learner autonomy, interaction, collaboration

\section{Introduction}

With the proliferation of the communicative and interactive approaches to English Language Teaching (ELT), 'learning by doing' or 'active learning' has become one of the prominent considerations of the classroom practitioners. In this regard, the predicament that the teachers frequently encounter is: how to engage and involve the learners directly in the class work to ensure their active participation in the learning process. Hence, collaborative learning or group learning has emerged as one of the practical ways to engage the learners in the learning process. Collaborative language learning is getting preference day by day because different researches and studies have shown that, if the students work on any problem or issue collaboratively, they can come up with more valid and implementable solutions than solving the issue individually. In group work, students can learn through cooperation and negotiation which increase their motivation and interest, and amplify their learning capacity. In this respect, to know whether group work enhances learning in the classroom, a case study (in a small scale) was conducted by the author that can be categorized as a kind of action research. Consequently, this article is based on the case study and its result, and thus is focused on the rationales behind group work, description of the techniques and procedures used in the study, and the findings (whether the rationales behind group work executed as true in the classroom practice).

\section{Literature Review}

In the arena of language teaching, nothing is fixed or static: the methods, techniques and procedures are dynamic, fluid and subject to constant change (Larsen-Freeman, 2004). As a consequence, when one method replaces another method over time, classroom techniques and procedures also get changed. For instance, in the Age of Methods (from 1950s to 1970s), individual student work used to dominate in the classroom. But later on during 1970s, with the advent of the ideas like 'learner centrism', 'learning is sharing' and most importantly, with the proliferation of Lev Vigotsky's ideas of interactive learning, group work brought a breakthrough into the traditional procedure of teaching and learning. Vigotsky believed learning as a product of social phenomenon which can be effectively shaped by social interaction (Frey, Fisher and Everlove, 2009). Hence, from Vigotsky's concept that learners will learn better if they interact with each other and solve any problem collaboratively, the idea of introducing and implementing group work in the classroom came to the scene. Finally, since Communicative Language Teaching (CLT) stepped into the arena of language teaching, group work has become a common occurrence in many of the classrooms. In this regard, lots of studies and researches are being conducted to find out whether group work can be an effective technique to engage the students in learning in the classroom. For example, Long and Porter (1985) discussed about 
how group work can be a beneficial tool to engage, involve and motivate the learners in the class. Harmer (2001) argued that group work facilitates learning as it creates a positive and interactive environment for the learners. Like the same way Rhoades (2013) also showed how group work can be used to manage a classroom efficiently. Not only that, he also described some strategies to ensure students' participation in the class through group work.

\section{Rationale for Group Work}

People actually learn language by using it and in group work students get the opportunity to use it properly. In the second language classroom situation, group work is being supported by various types of rationale like pedagogical, psycholinguistic etc. (Long and Porter, 1985). Actually, Long and Porter (1985) argues for five pedagogical arguments for the use of group work. The first argument is that, group work increases language practice opportunities. That is to say, when the students become involved in the group work, they get the chance to practice their language. On the other hand, when a lecture is organized in lockstep mode, the class becomes totally teacher centered and instruction based, where most of the class slot/period is taken by the teacher, not by the students.

The second argument is that, group work improves the quality of student talk. As summarized by Long and Porter (1985), group work enhances the quality of student talk in several ways. Firstly, in a small group, the face-to-face peer conversation is more natural than the teacher-student formal talk. Secondly, while working together for five/ten minutes in groups students engage in cohesive and coherent sequences of utterances rather than isolated chunks of words/utterances which develop their discourse competence. Thirdly, another research by Long, Adams, McLean, and Castanos (found in Long and Porter, 1985) shows that, while working together in groups, students take on roles and positions and eventually can practice a range of language functions related to those roles and positions.

The third rationale for group work is that, it helps individualized instruction. Individualized learning implies an "attempt to provide for differing learner needs within a class and to place a higher proportion of responsibility for learning on the shoulders of the learners themselves" (Ur, 1991, p-233). A group of students can work on different materials and can put on different roles suited to their requirements. Not only that, students can do so simultaneously, thereby avoiding the risk of boring other students who do not have the same problem( Long and Porter, 1985). In this way, group work can be the initial stage toward individualization of instruction.

The fourth rationale for group work is that it promotes a positive affective climate. That is to say, while working in groups, the affective filters of the students remain low in contrast to the public atmosphere of lockstep instruction. Moreover, a small group provides a comparatively intimate and supportive setting. In these ways, group work promotes a positive climate.

The fifth rationale for group work is that, it motivates the learners. Littlejohn (1983) in a study has shown that, learners felt less inhibited and freer to speak and made mistakes in small groups than in the teacher-led class.

\section{A Case Study}

To check whether the arguments for initiating group work are working out in the classroom, a case study was conducted which can be defined as an action research. There were two research questions:

a) Can the rationales behind group work be executed practically in the classroom practice to enhance students' quality participation?

b) Is it possible to manage a class successfully when the students are engaged in group work?

The subjects of this study were the first semester students of a renowned private university of Bangladesh and the class was conducted under the course English Language 1, which is a foundational course of English. For the research purpose, 60 students were chosen from two sections and among them, 30 students from section A were under control group and another 30 students from section B were under experimental group. The students were of low intermediate to high intermediate level of language proficiency. The objective of the lesson was to make the students knowledgeable of the comparative and contrastive structures and then check if they can implement the structures or not. In this regard, with section A, the teacher involved the students in individual work and with section $\mathrm{B}$, she engaged the learners in group work. Regarding the activity, at first an audio clip was played from where students needed to pick up the comparative and contrastive structures. After that, students were asked to come up with their own creative piece of writing (short story, poem or song) by using those structures (in section A, individually and in section B, in groups). As section B was the experimental group, the procedures and techniques of conducting that class will be described in detail. Hence, the procedures that were being followed to ensure the 
students' quality participation through group work are mentioned below:

\subsection{Forming Groups}

There are actually several ways of putting individual students in groups like friendship, streaming, chance and so on. Here, steaming approach has been followed which means dividing the students according to their ability. In this respect, Harmer (2001) suggests that groups should have a mixture of weaker and stronger students so that more proficient students can assist the less proficient ones. In the study, the researcher also followed the streaming approach to arrange the students in groups.

Next point was to decide the number of students in each group. As it is stated earlier that the number of students in section B were 30 , so five students in each group made six groups.

\subsection{Assigning Roles}

Within the groups, if the students are given some fixed/specific responsibility, they will be able to take charge of their own learning (Rhoades, 2013). Therefore, to promote learner autonomy, the teacher decided to assign the learners with some specific roles. At first, before assigning any role, the teacher wanted to assign a color card to each student by following Rhoades' (2013) 'rainbow learning' cooperative approach. That is to say, the colors were organized in such a way that it matches a rainbow: one student in each group was given purple card, another was given blue, another was green, another was orange and the fifth one was given red. As it is mentioned earlier, the groups were of mixed ability, that is, the groups encapsulated both weaker and stronger students; in this regard, the colors were distributed among the students in this way: red card was for the students with low level of language proficiency, orange was for the students who were reluctant to respond and participate in the class works, blue was for the students who were mediocre, purple was for them who had potentials and lastly, green card was for the students who had comparatively better language proficiency than the others. In this way, it was actually easier for the teacher to monitor the students more precisely with their strengths and weaknesses. For instance, in the conducted class, the teacher wanted to make sure the participation of the students who were reluctant to contribute in the class work. Thus, she focused majorly on the students with orange colored cards and it helped her to locate and remember accurately which students were weak and thus demand extra care and attention from the teacher. Not only that, this rainbow learning approach can also help to notice those students altogether who have better language proficiency and thus want to talk more and dominate the group.

Next comes the most important part: assigning each student an individual role to promote learner autonomy and to encourage students' self-initiation. In the case study, the following roles were combined with students' color cards:

\subsubsection{Purple: Group Leader}

The students having potentials were the respective group leaders. Their roles were to lead the groups through monitoring the activities of other group members, keeping them on track or on topic, co-ordinate and distribute the roles and the like. In this way, the students who were in the charge of group leaders could develop a sense of responsibility not only to monitor their own learning, but also to lead and guide others.

\subsubsection{Red: Recorder/Writer}

In that class, the students with low-level of language proficiency were in charge of writing the valid points after discussion of the group members. In this way, they got involved into the task directly. Not only that, in spite of their low level of language proficiency, they showed their sincerity while producing the write up because that was the end result of the whole group effort and they were majorly responsible for recording those.

\subsubsection{Green: Language Monitor}

The students having green color cards in each group were responsible for reminding the group members to keep practicing English while working in groups. As they were the students with comparatively better language proficiency, they actually tried to locate where the students were using incorrect English and they also provided some sort of corrections for them. In majority of the cases their corrections were appropriate. In some of the cases, the teacher actually needed to provide corrections.

\subsubsection{Orange: Participation Monitor}

The role of these students in each group was to monitor and ensure an even participation of all the group members. That is to say, the participation monitor will actually observe and check that every group member is equally participating in the group work: no one is sitting silently as well as no one is dominating. As students with orange cards were the reluctant ones, with their assigned roles they became more conscious about not only other's 
participation but also their own contributions in the group work.

\subsubsection{Blue: Time Monitor}

As the class time was limited and for each and every task a fixed segment of time was allocated, it was crucial that the group members complete their tasks within due time. For this reason, the time monitor was in charge of monitoring whether the group members are taking too much time on any task and also to remind others of the time frame of that task.

\subsection{Giving Instructions and Establishing Expectations}

For the group works to be effective and engaging, the instructions need to be delivered clearly. In the class, as the students were fresher and thus were not used to with color cards and putting up roles, it was necessary for me to provide instructions thoroughly and clearly. As different students are getting different roles, if the students do not get sufficient instruction of what to do and how to do, the group co-ordination can be hampered and the end-result may not be achieved. In this respect, the teacher needs to provide a clear outline for their task(s).

In addition to clear instructions, establishing expectations of how students should perform during the group work is also of prime concern. In this respect, Rhoades (2013) instructs the teachers to discuss expectations with students and decide together. For instance, in the conducted class, the teacher together with her students decided the major expectations for the group work:

$>$ Even participation and contribution of all the group members while working

$>$ Discussions and arguments among the group members but no chaos in the class and the like.

\subsection{Minimizing Chaos}

The researchers like Harmer (2001) and Rhoades (2013) have found that it is many of the teachers' notion that if the students become engaged in group work, the class will be chaotic, disorganized and eventually the teacher will lose control over the class. In reality, if the teacher can use the above mentioned techniques-assigning colors and roles to the students, set the instructions and expectations- eventually, the chaos can be minimized to a great extent. Not only that, the teacher's proper monitoring and feedback can make the group work organized and fruitful.

\section{Ensuring Quality Learning through Group Work}

Now, it is time to consider whether this conducted class is supporting the rationales for group work and how the group work is facilitating quality learning. In this respect, the first argument was- group work increases language practice opportunities. In that particular task, the group members were required to exchange their views, discuss among themselves, give directions to each other (like 'do it in this way' or 'do not write it here' etc.) and finally produce the creative piece of writing after much negotiation and logical arguments. And for doing all these things, the students had to use English to converse among themselves. If the task were given individually, then definitely the students would not get the chance to practice this much language there. That is why, the students of section A did not get the opportunity to practice language in the class. So it can be said that, in comparison to the individual work, group work increases language practice opportunities.

The second rationale was- group work increases the quality of student talk. In the group work, the students got involved in face to face, real life communication, not the artificial one. Moreover, while preparing the task, they actually developed some conversational skills like suggesting, inferring, accepting/rejecting, proposing, qualifying/disqualifying, agreeing/disagreeing and so on. On the other hand, the students of section A could not get this chance as they got involved in individual work. So in group work, the students could practice a wide range of language functions related to their assigned roles. In these ways actually the group work contributed to enhance the quality of students' talk.

The third rationale was, group work facilitates individualized instruction. In the case study, individual differences of the learners were acknowledged. For example, the students who had better language proficiency got the role of language monitor. Like the same way, the students who had potentials to take decision and to lead the group, became the group leaders. In this way, individual learner differences were acknowledged in the group work. On the contrary, in the controlled group, the students had to work individually and there were no specific roles for the students to be followed.

The fourth rationale was that, group work promotes a positive affective climate. With the controlled group-where they took part in individual activity- it was observed that many students, who were introvert, shy or linguistically not 
proficient, faced anxiety and stress while performing in front of the whole class. On the other hand, while participating in group work, as the teacher noticed in the class, the weaker students found a relatively 'intimate setting' and 'a more supportive environment' (Long and Porter, 1985) by dint of which they tried to initiate responses and shared their views (though not always correctly) with the other group members.

The last rationale was group work motivates learners. In the conducted study, it was found that, as the students of the experimental group were carrying out certain roles, they became more confident and enthusiastic about their participation and contribution in the group than that of the controlled group. It seemed that the students were much more motivated to learn.

Up to this point, it seems that, the rationales behind group work executed as true in the classroom practice. Moreover, it was easier for the teacher to monitor and instruct the small groups in contrast to the whole class at the same time. As a result, classroom management was also reached to a standard level.

\section{Conclusion and Implications}

Nowadays, lots of strategies and techniques are being used to engage the learners in the learning process and group work has emerged as one of the mostly used and convenient strategies. For a group work to be carried out successfully in the class, apart from the students' engagement, the teacher also needs to provide clear instruction, set the expectations and then monitor the whole process efficiently. Only than the rationales behind group work can be established as valid and fruitful in the classroom practice. In line with the theory, one of the practical implications of this study can be to introduce group work in the semi-large or large classrooms to ensure the students' active participation in the learning process. Secondly, during group work, assigning specific roles to the students can promote learner autonomy and also can acknowledge individual learner differences. Thirdly, it will be convenient for the teacher as well to guide and facilitate small groups rather than the whole class together. Lastly, the syllabus designers and material developers can also focus on the apparent triumph of group work over individual work and can incorporate necessary changes and adjustments in their plans accordingly.

\section{References}

Frey, N., Fisher, D., \& Everlove, S., (2009). Productive Group Work. Retrieved from http://www.ascd.org/publications/books/109018/chapters/Defining-Productive-Group-Work.aspx

Harmer, J. (2001). The practice of English language teaching. London: Longman.

Larsen-Freeman, D. (2004). Techniques and principles in language teaching. New Delhi: Oxford University Press.

Littlejohn, A. P. (1983). Increasing learner involvement in course management. TESOL Quarterly, 17(4), 595-608. http://dx.doi.org/10.2307/3586615

Long, M. H., \& Porter P. A. (1985). Group work, interlanguage talk, and second language acquisition. TESOL Quarterly, 19(2), 207-228. http://dx.doi.org/10.2307/3586827

Rhoades, G. (2013). Minimizing the chaos through cooperative classroom management. English Teaching Forum, 4, 28-34.

Ur, P. (1991). A course in language teaching: practice and theory. Cambridge: Cambridge University Press. 